\title{
Impact of crop stand, Rhizobium inoculation, and foliar fertilization on pea root parameters
}

\section{Einfluss von Pflanzenbestand, Rhizobium-Inokulation und Blattdüngung auf die Wurzelparameter der Erbse}

\author{
Agnieszka Klimek-Kopyra ${ }^{1 *}$, Reinhard W. Neugschwandtner ${ }^{2}$, Tomasz Gląb ${ }^{3}$, Andrzej Oleksy ${ }^{1}$, Tadeusz Zając ${ }^{1}$
}

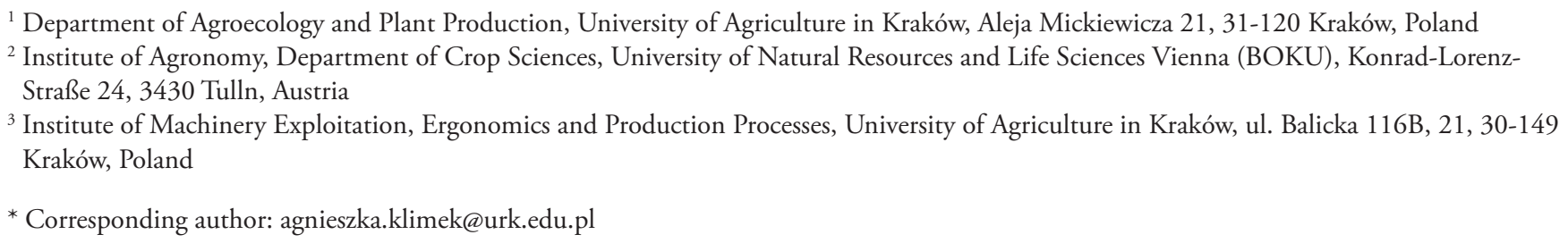

Received: 1 April 2020, received in revised form: 13 May 2020, accepted: 14 May 2020

\begin{abstract}
Summary
Ecological intensification of crop production involves the use of intercrops and the rational use of inoculation and fertilization in case of intercrops including legume species. The root system plays an important role in the productivity of crops. Therefore, effects of the inoculation treatments (Nitragina) or foliar fertilization (Photrel) or a combination of both were assessed on root parameters of pea grown as pure stand or intercrops with linseed or wheat in a 3-year experiment in Poland. Crop stand composition influenced the root parameters of pea with a higher root length density (RLD) in the root fractions of $0.1-1 \mathrm{~mm}$ of pea in pea/linseed intercrops than in the pure stand, a higher mean root diameter (MRD) in pure pea and intercrops of pea with linseed than with wheat, and also a tendency of a higher root dry matter (RDM) in pure pea and pea/linseed than in pea/wheat in 2 out of the 3 years. RLD was higher with Photrel than with Nitragina in root fractions of $0.1-0.5 \mathrm{~mm}$. Treatments did not affect the MRD, but a combination of Nitragina + Photrel increased the RDM in 1 year. Intercropping of pea with linseed and the application of a foliar fertilizer might be a strategy to improve pea root characteristics.
\end{abstract}

Keywords: Pisum sativum, morphological root traits, intercropping, inoculation, foliar fertilization

\section{Zusammenfassung}

Die ökologische Intensivierung der Pflanzenproduktion beinhaltet die Verwendung von Pflanzengemengen und den sinnvollen Einsatz von Inokulation und Düngung, wenn Leguminosen in Gemengen eingesetzt werden. Das Wurzelsystem spielt eine wichtige Rolle für die Produktivität von Pflanzen. Daher wurde in einem dreijährigen Experiment in Polen die Wirkung der Behandlungen Rhizobium-Inokulation (Nitragina) oder Blattdüngung (Photrel) oder einer Kombination aus beiden auf die Wurzelparameter von Erbsen untersucht, die als Reinsaat oder im Gemenge mit Lein oder Weizen angebaut wurden. Die Pflanzenbestände beeinflussten die Wurzelparameter von Erbsen mit einer höheren Wurzellängendichte (RLD) der Erbse im Gemenge mit Lein als in der Reinssat in den Wurzelfraktionen von 0,1-1 mm, einem höheren mittleren Wurzeldurchmesser (MRD) in der Erbsenreinsaat und dem Gemenge mit Lein als im Gemenge mit Weizen und auch eine Tendenz zu einer höheren Wurzeltrockenmasse (RDM) in der Erbsenreinsaat und dem Gemenge mit Lein als im Gemenge mit Weizen in zwei von drei Jahren. Die RLD war mit Photrel in den Wurzelfraktionen von 0,1-0,5 mm höher als mit Nitragina. Die Behandlungen hatten keinen Einfluss auf die MRD, aber eine Kombination von Nitragina + Photrel erhöhte die RDM in einem Jahr. Die Wurzelknöllchen pro Pflanze wurden durch die Pflanzenbestände und Behandlungen nicht beeinflusst. Es gab einen signifikanten Jahreseffekt auf die MRD, die RDM und die Knöllchen pro Pflanze, jedoch nicht auf die RLD. Der Gemengeanbau von Erbse mit Lein und Blattdünung kann eine Strategie für die Verbesserung der Wurzelcharakteristik der Erbse sein.

Schlagworte: Pisum sativum, morphologische Wurzeleigenschaften, Gemengeanbau, Inokulation, Blattdüngung 


\section{Introduction}

Roots are a fundamental part of the plant. They are needed to absorb water and nutrients for growth (Smucker, 1993). Optimum root growth is especially crucial in arid areas or in regions with temporary drought, because in such conditions crops may have limited access to water and nutrients (Lynch, 2013). Songsri et al. (2009) stated that root parameters are important traits for water efficiency under moderate and severe drought and that genotypes with larger root systems could maintain a relatively higher water efficiency under water stress conditions compared to those with a smaller root system.

Morphological root traits, such as root length, root diameter, and root dry matter, are key determinants of plant resistance to adverse habitat conditions (Laio et al., 2006; Bodner et al., 2013; Klimek-Kopyra et al., 2017). Ingram et al. (1994) noted that root thickness determines drought resilience of plants and that root length density (RLD) enables water uptake. Root biomass is dependent on root diameter (Eissenstat and Yanai, 2002), and biomass production increases with a larger root diameter because of better developed transport of water and nutrients (Qaderii et al., 2019). Klimek-Kopyra et al. (2015a) indicated that variation of morphological root traits differs between crop stands (pure stands versus intercrops) and soil types; the average root diameter of pea grown in a Luvic Phaeozem was higher for pure grown pea compared to pea intercropped with linseed, whereas it was the other way around in a Eutric Cambisol.

Drought resistance can be improved by changing the plant to increase the efficiency of water uptake by a root system better adapted to drought. This can be done by breeding new cultivars with altered root plasticity, capable of effectively acquiring both deep and shallow water and nutrients' resources (Ho et al., 2005; Tron et al., 2015; Lynch 2018). Successful results of biological progress regarding changes in root morphology are noticeable mainly in legumes, such as chickpea, cowpea, soybean, field pea, and white clover, which are most sensitive to water deficiency during growth and development (Matsui and Singh, 2003; Annicchiarico and Piano, 2004; Benjamin and Nielsen, 2006). Under dry conditions, the right cultivar selection in combination with proper agrotechnical treatments can mitigate yield losses (Klimek-Kopyra et al., 2018a; 2019). The distribution of RLD in pea was indicated by Klimek-Kopyra et al. (2018a) to be affected by the interaction of pea cultivars $x$ years, with a fodder cultivar of pea obtaining a higher
RLD in a semi-drought year compared to a food cultivar in a very humid year. A significant interaction between seed inoculations and years was also proven with a gel seed inoculant, which significantly increased the RLD compared to a powder inoculant in a dry year, whereas the gel inoculant was least effective in a humid year.

Another approach was presented by Fernández and Eichert (2009), who indicated that foliar fertilization can effectively reduce the negative effects of unfavorable weather conditions in crop growth by reducing the negative impact of soil effects that limit the uptake of hard-to-reach nutrients by plant roots. Foliar fertilization has many advantages if used during the plant ripening period, when the root system is inefficient, by effectively complementing shortages of micro- and macronutrients (Wójcik, 2004). However, the effectiveness of foliar fertilization may depend on the physiological state of the plant, for example, osmotic potential of the roots, hydraulic conductance, or nutrient status (Weinbaum, 1988). Wójcik (2004) indicated that foliar fertilization is most effective when soil nutrient availability is low in the dry topsoil and root activity during the reproductive stage is low. Similar to that, Klimek-Kopyra et al. (2018a) have shown that under periodic drought conditions, foliar fertilization significantly increased the weight of pea roots, whereas a combination of Rhizobium inoculation and foliar fertilization significantly increased the RLD. Another study by Klimek-Kopyra et al. (2018b) showed that Rhizobium inoculation together with foliar fertilization effectively promoted the growth of biomass and pea yield components, suggesting that foliar fertilization can also effectively affect pea underground biomass, minimizing its reduction in intercrops of pea with linseed. Current literature does not show the influence of Rhizobium inoculation and foliar fertilization on root system development in the condition of pea intercrops with linseed or wheat. The aim of the research was therefore to show the effect of crops stands (pure stands versus intercrops) and the single treatments of Rhizobium inoculation and foliar fertilization as well as a combination of both on pea roots parameters.

\section{Material and Methods}

\subsection{Experimental site and environmental conditions}

A field experiment was conducted in 2009-2011 in Modzurów in Silesia (Poland; 50 $09^{\prime} \mathrm{N} 18^{\circ} 07^{\prime} \mathrm{E}$ ). The soil of the 
experiment was a Haplic Phaeozem (WRB 2015) characterized by $\mathrm{pH} 6.3$ and 19.1, 21.7, and $10.1 \mathrm{mg}$ of available phosphorus, potassium, and magnesium, respectively, per $100 \mathrm{~g}$ of soil in the top soil layer.

The weather conditions varied among the experimental years (Table 1). In the first experimental year (2009), it was much warmer in April and May and cooler in June compared to the subsequent vegetation seasons. Air temperature during 2010 and 2011 was similar and adequate for plant development. The highest temperature was noted at the end of the maturity stage (July), whereas the lowest temperature was noted during sowing (end of March). In 2009, there was a high amount of precipitation in March but a low amount in April. The vegetation period in 2010 was the wettest among all three experimental years, mostly because of very high precipitation in May and July. In 2011, there were lower amounts of rainfall than in 2010 but higher amounts than in 2009 in all months except March and June.

\subsection{Experimental factors}

A two-factorial field experiment was set up in a spilt-plot design with treatment as the main plot factor and crop stand as the subplot factor. Three replications were performed. The plot size was $9 \mathrm{~m}^{2}$. The factor treatment included: Rhizobium leguminosarum inoculation (Nitragina), foliar fertilization (Photrel), and combination of Nitragina + Photrel. Inoculation of pea seeds with Rhizobium inoculant Nitragina was performed 1 day before sowing. One day before sowing, all pea seeds were also dressed with the fungicide Funaben T 75 DS/WS. Foliar fertilizer Photrel (150 g of B, $210 \mathrm{~g}$ of Mn, $12 \mathrm{~g}$ of Mo, $400 \mathrm{~g}$ of $\mathrm{MgO}$, and $1.08 \mathrm{~g} \mathrm{SO}_{3}$ was applied at the beginning of the plant budding stage (BBCH 51) in the amount of $3 \mathrm{~L} \mathrm{ha}^{-1}$.
The factor crop stand included: pure pea and intercrops of pea/linseed and pea/wheat intercrops.

\subsection{Experimental management}

Pure stands of pea (Pisum sativum L., cv. Tarchalska), wheat (Triticum aestivum L., cv. Koksa), and linseed (Linum usitatissimum L., cv. Szafir) were established with 120 (pea) and 480 (wheat and linseed) germinable seeds per meter square. For intercrops, half of the sowing density of the pure stands was used for both partners. Intercrops were sown individually with an $\mathrm{Oyord}^{\circledR}$ plot drill because of the different sowing depth requirements of crops. Sowing depth was $6 \mathrm{~cm}$ for pea, $3 \mathrm{~cm}$ for wheat, and $2 \mathrm{~cm}$ for linseed. Row spacing was $15 \mathrm{~cm}$. Pea was sown first, whereas companion crop were sown second. Sowing was conducted in early April in each year. The forecrop was winter wheat in all 3 years. The crops were fertilized with $48 \mathrm{~kg} P$ $\mathrm{ha}^{-1}$ and $72 \mathrm{~kg} \mathrm{~K} \mathrm{ha}^{-1}$. Pure pea received $20 \mathrm{~kg} \mathrm{~N} \mathrm{ha}^{-1}$ and intercrops received $40 \mathrm{~kg} \mathrm{~N} \mathrm{ha}^{-1}$. Intercrops of pea with linseed or wheat were fertilized with $40 \mathrm{~kg} \mathrm{~N} \mathrm{ha}^{-1}$. Herbicides were applied for weed control directly after sowing the same each year: Command ${ }^{\mathrm{TM}} 480 \mathrm{EC}\left(0.2 \mathrm{~L} \mathrm{ha}^{-1}\right)$ + Afalon Dyspersyjny ${ }^{\mathrm{TM}} 450\left(1.0 \mathrm{~L} \mathrm{ha}^{-1}\right)$ and Basagran ${ }^{\mathrm{TM}}$ $480 \mathrm{SL}\left(2.8 \mathrm{~L} \mathrm{ha}^{-1}\right)$. Harvest was performed in the beginning of August in each year with a plot combine harvester.

\subsection{Experimental measurements}

Roots samples were collected at full flowering of pea from the humus horizon $(0-30 \mathrm{~cm})$ with an Ejikelkamp ${ }^{\oplus}$ probe. The cylinder excavated was $7 \mathrm{~cm}$ in diameter and $15 \mathrm{~cm}$ in height. The samples were taken two times. Root-soil samples were washed with an automatic hydropneumatic

Table 1. Weather conditions in the experimental years (2009-2011) and the long-term average (1977-2007) from March to July Tabelle 1. Wetterverhältnisse in den Versuchsjahren (2009-2011) und der langjährige Durchschnitt (1977-2007) von März bis Juli

\begin{tabular}{|c|c|c|c|c|c|c|}
\hline Weather conditions & Year & March & April & May & June & July \\
\hline \multirow{3}{*}{ Temperature $\left({ }^{\circ} \mathrm{C}\right)$} & 2009 & 3.8 & 12.5 & 14.2 & 15.9 & 20.0 \\
\hline & 2010 & 4.0 & 7.5 & 11.7 & 16.7 & 20.4 \\
\hline & 2011 & 2.0 & 9.7 & 13.2 & 17.4 & 17.3 \\
\hline Long-term average & & 8.3 & 13.6 & 16.4 & 18.2 & 17.9 \\
\hline \multirow{3}{*}{ Precipitation $(\mathrm{mm})$} & 2009 & 96.6 & 5.6 & 55.2 & 109.2 & 137 \\
\hline & 2010 & 17.0 & 66.5 & 193.2 & 103.5 & 208.5 \\
\hline & 2011 & 31.1 & 29.2 & 71.5 & 99.5 & 167.5 \\
\hline Long-term average & & 48.0 & 65.0 & 66.0 & 78.0 & 76.0 \\
\hline
\end{tabular}


root scrubber (using tap water with approximately $2 \mathrm{dm}^{-3}$ $\left.\mathrm{min}^{-1}\right)$. The root sample washing cycle lasted for $3 \mathrm{~min}-$ utes and had two stages. The first stage of washing lasted for 2 minutes with an air pressure of $100 \mathrm{kPa}$. The second stage lasted for 1 minute with an air pressure of $300 \mathrm{kPa}$. Washed roots were transferred on to a filter paper to remove excess water and to count root nodules. The root separation was performed properly based on the visible morphological differences between roots of the species (with the roots of pea being yellow and covered by nodules). After separation of roots and nodules, root nodules-separated from roots-were located on a transparent foil and scanned with an Epson Perfection 4870 Photo $^{\oplus}$ with 600 dpi resolution. Scans were saved in TIFF format. Roots as well as root nodules were dried at $105^{\circ} \mathrm{C}$ for $48 \mathrm{~h}$. Roots' scans were analyzed with an APHELION v.3.2 image analyzer. On the basis of the results, the following indices were calculated:

- $\operatorname{RLD}\left(\mathrm{cm} \mathrm{cm}^{-3}\right)=\mathrm{L} / \mathrm{V}$, where $\mathrm{L}$ is the root length $(\mathrm{mm})$ and $\mathrm{V}$ is the volume of the sample $\left(\mathrm{cm}^{3}\right)$

- Mean root diameter (MRD, mm), calculated as a weighted average root diameter

- Root dry mass (RDM, $\mathrm{mg} \mathrm{cm}^{-3}$ )

The competitive effect between species can be calculated using the competitive effect indicator (ICE), which was described by Rudnicki and Jaskulski (2006) for the aboveground competition of crops and weeds. It is based on the relative difference in biomass, thus allowing to define and to compare reactions of one crop to another in intercrops. We implemented this index to the interspecific belowground competition of roots between species $\left(\mathrm{ICE}_{\mathrm{ROOT}}\right)$. Therefore, the RDM of pea in the pure crop stand was compared with its RDM in the two intercrops. The indicator was calculated as follows:

$$
\text { - } \operatorname{ICE}_{\mathrm{ROOT}}(\%)=\left(\mathrm{RDM}_{\mathrm{PS}}-\mathrm{RDM}_{\mathrm{IC}}\right) \times 100 / \mathrm{RDM}_{\mathrm{PS}}
$$

where $\mathrm{RDM}_{\mathrm{PS}}$ is the RDM of the species in the pure stand and $\mathrm{RDM}_{\mathrm{IC}}$ the RDM of the species in the intercrop.

The $\mathrm{ICE}_{\mathrm{ROOT}}$ presents the relative difference of the "root mass" of a single plant of pea in a pure stand compared to intercrop. The greater the positive value of the indicator, the stronger is the competition of the companion crop towards pea. Zero or a value close to zero indicates the lack of such competition. A negative value indicates a stimulating effect of the companion crop on pea. The RDM data used for the ICE index are based on individual plants (per plant) and not per area $\left(\mathrm{m}^{2}, \mathrm{ha}\right)$.

\subsection{Statistics}

The results were statistically analyzed by the analysis of variance using Statistica 10.0 software (Stat Soft, Inc., USA). Significant differences for traits were verified using the Tukey test at the significance level of $\mathrm{p}<0.05$.

\section{Results}

The RLD did not differ between years and crop stands but was significantly higher after foliar fertilizer application by Photrel having higher values than Nitragina and Nitragina + Photrel, showing intermediate values (Table 2). The RLD was ranked as follows in the individual root fractions (root diameter in mm): $0.1-0.2>0.2-0.5>0.5-1>0.05-$ $0.1>1-2>$ in fractions of $>2$ and $<0.05$ (mean overall years, crops stands, and treatments; Table 3 ). Although total RLD did not differ between crop stands, there was a significant interaction of crop stand $\times$ root fractions and also a significant interaction of treatment $\times$ root fractions. Pure pea had a lower RLD in the root fraction of $0.1-$ $0.2 \mathrm{~mm}$ than in intercrops with linseed and wheat; in the root fractions $0.2-0.5$ and $0.5-1 \mathrm{~mm}$, the RLD of pea/linseed was highest, with no significant differences between crop stands in other root fractions ( $<<0.001$, Figure $1 \mathrm{~A})$. Among treatments, the RLD was highest with Photrel and lowest with Nitragina with Nitragina + Photrel showing intermediate values in the three root fractions from 0.1 to $1 \mathrm{~mm}$, with no significant differences between treatments in other root fractions $(\mathrm{p}<0.001$, Figure $1 \mathrm{~B})$.

There was a significant year $\times$ crop stand effect on the MRD: the MRD of pea for main effects was ranked as follows: $Y$ - $2009>2010>2011$; - pea/linseed, pure pea > pea/wheat. In 2009, the MRD did not differ among crop stand, whereas in 2010 and 2011, the MRD of pea/wheat tended to be lower than that of pure pea and pea/linseed. Treatment did not affect the MRD (Tables 2 and 4).

The RDM of pea for main effects was ranked as follows: $Y-2011>2009$, 2010; Nitragina + Photrel $\geq$ Nitragina $\geq$ Photrel, with no main effects of crop stand. However, there were significant interactions of year $\times$ crop stand, year $x$ treatment, and crop stand $x$ treatment (Table 5). The year $\times$ crop stand interaction was given as follows: RDM tended to be lower in pea/wheat than in pure pea and pea/ linseed in 2010 and 2011, whereas, in 2009, it tended to be lowest in pure pea compared to the other treatments. The difference of RDM between 2009 and 2011 was lower 
for pea/wheat than for other crop stands. The year $\times$ treatment interaction was given as follows: RDM of pea was significantly higher with Nitragina + Photrel than with the other treatments only in 2011, whereas no differences between treatments occurred in 2009 and 2010. The crop stand $\times$ treatment interaction was given as follows: RDM of pea tended to be higher with Nitragina + Photrel than the two other treatments in pure pea and pea/linseed and with Nitragina and Nitragina + Photrel than with Photrel in pea/wheat.

The $\mathrm{ICE}_{\mathrm{ROOT}}$ indicator shows that the RDM of pea in the pea/linseed intercrop was higher in all 3 years than in the pure stand and the RDM of pea in the pea/wheat intercrop was higher in 2009 but was lower in 2010 and 2011 than in the pea pure stand (Table 6).

Number of root nodules per plant among years was ranked as follows: $2011>2009>2010$. Crop stand and treatment did not affect the number of root nodules per plant (Table 2).

\section{Discussion}

Current research indicates that there are significant interactions between legumes and non-legume crops in intercropping, affecting above-ground biomass production, formation of yield components, plant height, and stem and leaf characteristics (Zaja,c et al., 2013; Neugschwandtner and Kaul, 2014; Klimek-Kopyra et al., 2020) and the uptake and use efficiency of macro- and micronutrients (Neugschwandtner and Kaul, 2015, 2016a, 2016b; Zając et al., 2018). Under Central European conditions, grain and biomass yield advantages have been shown for intercrops of naked oat/faba bean (Klimek-Kopyra et al., 2015b) and wheat/rapeseed (Ebrahimi et al., 2017). Klimek-Kopyra et al. (2018b) also indicated a negative effect of intercropping on selected physiological parameters with a significant reduction in the green area index (GAI) and the normalized difference vegetation index (NDVI) values in pea/ linseed intercrops. Zając et al. (2013) noticed that mutual

Table 2. Effect of year, crop stand, and treatments on pea root parameters

Tabelle 2. Einfluss von Jahr, Pflanzenbestand und Behandlung auf die Wurzelparameter von Erbse

\begin{tabular}{|c|c|c|c|c|c|}
\hline & & $\begin{array}{c}\text { RLD } \\
\left(\mathrm{cm} \mathrm{cm}^{-3}\right)\end{array}$ & $\begin{array}{l}\text { MRD } \\
(\mathrm{mm})\end{array}$ & $\begin{array}{c}\mathrm{RDM} \\
\left(\mathrm{mg} \mathrm{cm}^{-3}\right)\end{array}$ & $\begin{array}{c}\text { Root nodules } \\
\left(\text { plant }^{-1}\right)\end{array}$ \\
\hline \multirow[t]{3}{*}{ Year $(Y)$} & 2009 & 0.398 & $0.537^{a}$ & $0.310^{\mathrm{b}}$ & $24.8^{\mathrm{b}}$ \\
\hline & 2010 & 0.454 & $0.402^{b}$ & $0.309^{\mathrm{b}}$ & $15.9^{c}$ \\
\hline & 2011 & 0.420 & $0.366^{c}$ & $0.476^{a}$ & $30.2^{\mathrm{a}}$ \\
\hline \multirow[t]{3}{*}{ Crop stand $(S)$} & Pure pea & 0.398 & $0.437^{a}$ & 0.357 & 20.6 \\
\hline & Pea/linseed & 0.492 & $0.450^{\mathrm{a}}$ & 0.372 & 20.5 \\
\hline & Pea/wheat & 0.430 & $0.408^{b}$ & 0.338 & 18.7 \\
\hline \multirow[t]{3}{*}{ Treatment $(\mathrm{T})$} & Nitragina & $0.380^{\mathrm{b}}$ & 0.421 & $0.355^{\mathrm{ab}}$ & 19.1 \\
\hline & Photrel & $0.471^{a}$ & 0.434 & $0.332^{\mathrm{b}}$ & 20.7 \\
\hline & Nitragina + Photrel & $0.426^{\mathrm{ab}}$ & 0.446 & $0.379^{\mathrm{a}}$ & 20.7 \\
\hline \multicolumn{6}{|l|}{ ANOVA } \\
\hline Year $(\mathrm{Y})$ & & ns & $* * *$ & $* * *$ & $* *$ \\
\hline Crop stand (S) & & ns & * & ns & ns \\
\hline Treatment (T) & & * & $\mathrm{ns}$ & $* *$ & ns \\
\hline$Y \times S$ & & ns & * & $*$ & ns \\
\hline $\mathrm{Y} \times \mathrm{T}$ & & ns & $\mathrm{ns}$ & $* * *$ & ns \\
\hline $\mathrm{S} \times \mathrm{T}$ & & ns & ns & * & ns \\
\hline $\mathrm{Y} \times \mathrm{S} \times \mathrm{T}$ & & $\mathrm{ns}$ & $\mathrm{ns}$ & $* * *$ & $\mathrm{~ns}$ \\
\hline
\end{tabular}

$\mathrm{RLD}=$ root length density; $\mathrm{MRD}=$ mean root diameter, $\mathrm{RDM}=$ root dry mass, $\mathrm{ns}=$ not significant, significant differences at $\mathrm{p}<0.05\left(^{*}\right)$, $\mathrm{p}<0.01\left(^{* *}\right)$ and $\mathrm{p}<0.001\left(^{* * *}\right)$. Different letters indicate significant differences between means. 
Table 3. Root length density (RLD) distrubution depending on root fractions

Tabelle 3. Verteilung der Wurzellängendichte (RLD) in Abhängigkeit der Wurzelfraktionen

\begin{tabular}{cc}
\hline Root Fractions (root diameter in mm) & $\operatorname{RLD}\left(\mathrm{cm} \mathrm{cm}^{-3}\right)$ \\
\hline $0.05-0.1$ & $0.3421^{\mathrm{d}}$ \\
$0.1-0.2$ & $1.1719^{\mathrm{a}}$ \\
$0.2-0.5$ & $1.0636^{\mathrm{b}}$ \\
$0.5-1$ & $0.5904^{\mathrm{c}}$ \\
$1-2$ & $0.1789^{\mathrm{e}}$ \\
$>2$ & $0.0511^{\mathrm{f}}$ \\
p-value & $* * *$ \\
\hline
\end{tabular}

Significant difference at $\mathrm{p}<0.001{ }^{(* * *)}$. Different letters indicate significant differences between means.

aggressiveness between species is higher in less favorable weather conditions when the development of one species is overly favored.

Competition among crops not only affects yield structure but may also affect root parameters such as root length, root distribution, and root density (Craine and Dybzinski, 2013). Intra-specific belowground competition of roots between species was observed in our studies. The MRD and RDM of pea tended to be higher in pure pea and pea/ linseed intercrops compared to pea/wheat intercrops in 2 of the 3 years. Furthermore, soil type is affecting the root parameters of pea grown in pure or in intercrops (KlimekKopyra et al., 2015a). Jensen et al. (2007) revealed that root systems demonstrate a high level of plasticity in response to the local heterogeneity of soil profile and plant density. These findings were supported by Klimek-Kopyra et al. (2015a) who showed that environment strongly determines the level of interspecies competition: legumes grown on a rich soil competed better with linseed than under pure soil conditions, where species grown in intercrops had generally lower values of RLD, MRD, and RDM. Also, our findings confirm that in unfavorable weather conditions,

Table 4. Mean root diameter (MRD) depending on year $\times$ crop stand Tabelle 4. Mittlerer Wurzeldurchmesser (MRD) in Abhängigkeit von Jahr $\times$ Pflanzenbestand

\begin{tabular}{lccc}
\hline & \multicolumn{3}{c}{ MRD $(\mathrm{mm})$} \\
\cline { 2 - 4 } 2009 & Pure pea & Pea/linseed & Pea/wheat \\
\cline { 2 - 4 } 2010 & $0.534^{\mathrm{a}}$ & $0.529^{\mathrm{a}}$ & $0.553^{\mathrm{a}}$ \\
2011 & $0.409^{\mathrm{bc}}$ & $0.436^{\mathrm{b}}$ & $0.334^{\mathrm{c}}$ \\
\hline
\end{tabular}

Different letters indicate significant differences between means. the cultivation of pea/wheat intercrop was less valuable compared to pure pea stand.

Zając et al. (2012) analyzed morphological-developmental reactions of pea in pure stand to the application of seed inoculation of Nitragina and application of Nitragina in combination with foliar micronutrient fertilization of Photrel. They found both to be effective for mitigating unfavorable weather conditions, proving that the pre-inoculation of pea with Nitragina resulted in an increase in selected plant parameters and biomass yield. Pea seed inoculation in combination with foliar fertilization also increased the number of nodes per plant, which was particularly evident in a year with climatic conditions less favorable for plant growth. As a result, Zając et al. (2012) concluded that the highest seed yield per single plant of pea was achieved as an effect of the combined treatments application. Our results showed an increase in RDM in selected years and crop stands with a combined application of treatments, but no differences were observed compared to single treatments of Nitragina or Photrel for RLD, MRD, and the number of root nodules per plant. Photrel showed a higher RLD of the root fraction $0.1-0.5 \mathrm{~mm}$ compared to Nitragina. Klimek-Kopyra et al. (2018b) found that the use of Nitragina and Photrel improved the yield and yield structure of

Table 5. Root dry mass (RDM) depending on year $\times$ crop stand, year $\times$ treatment and crop stand $\times$ treatment

Tabelle 5. Wurzeltrockenmasse (RDM) in Abhängigkeit von Jahr $\times$ Pflanzenbestand, Jahr $\times$ Behandlung und Pflanzenbestand $\times$ Behandlung

\begin{tabular}{|c|c|c|c|}
\hline & \multicolumn{3}{|c|}{$\operatorname{RDM}\left(\mathrm{mg} \mathrm{cm}^{-3}\right)$} \\
\hline & Pure pea & Pea/linseed & Pea/wheat \\
\hline 2009 & $0.286^{c}$ & $0.332^{\mathrm{bc}}$ & $0.336^{\mathrm{bc}}$ \\
\hline 2010 & $0.315^{\mathrm{bc}}$ & $0.327^{\mathrm{bc}}$ & $0.264^{c}$ \\
\hline \multirow[t]{2}{*}{2011} & $0.491^{\mathrm{a}}$ & $0.497^{\mathrm{a}}$ & $0.415^{\mathrm{ab}}$ \\
\hline & Nitragina & Photrel & $\begin{array}{c}\text { Nitragina }+ \\
\text { Photrel }\end{array}$ \\
\hline 2009 & $0.334^{\mathrm{cd}}$ & $0.288^{d}$ & $0.309^{\mathrm{d}}$ \\
\hline 2010 & $0.309^{\mathrm{d}}$ & $0.313^{\mathrm{d}}$ & $0.304^{\mathrm{d}}$ \\
\hline \multirow[t]{2}{*}{2011} & $0.429^{\mathrm{b}}$ & $0.428^{\mathrm{bc}}$ & $0.562^{\mathrm{a}}$ \\
\hline & Nitragina & Photrel & $\begin{array}{c}\text { Nitragina }+ \\
\text { Photrel }\end{array}$ \\
\hline Pure pea & $0.343^{\mathrm{ab}}$ & $0.347^{\mathrm{ab}}$ & $0.379^{a}$ \\
\hline Pea/linseed & $0.360^{\mathrm{ab}}$ & $0.361^{\mathrm{ab}}$ & $0.390^{\mathrm{a}}$ \\
\hline Pea/wheat & $0.381^{\mathrm{ab}}$ & $0.268^{\mathrm{b}}$ & $0.364^{\mathrm{ab}}$ \\
\hline
\end{tabular}

Different letters indicate significant differences between means. 
Table 6. The ISCROOT indicator (\%) for comparing root dry matter of pea in pure stand versus intercropping

Tabelle 6. Der ISCROOT-Indikator (\%) für den Vergleich der Wurzeltrockenmasse von Erbse in der Reinsaat versus im Gemengeanbau

\begin{tabular}{lcc}
\hline & \multicolumn{2}{c}{$\mathrm{ICE}_{\text {ROOT }}{ }^{1}$} \\
\cline { 2 - 3 } 2009 & Pea/linseed & Pea/wheat \\
\cline { 2 - 3 } 2010 & -14.3 & -16.1 \\
2011 & -1.24 & 13.0 \\
\hline
\end{tabular}

${ }^{1}$ Positive value $=$ stronger competition of the companion crop toward pea. Negative value $=$ stimulating effect of the companion crop on pea.

species in intercrops of pea/linseed and pea/wheat under unfavorable weather conditions. Nitragina significantly increased the number of seeds per pod and seeds per stem of pea, whereas Nitragina + Photrel decreased straw weight and spike length for wheat intercropped with pea.

The aim of our study was to assess the impact of the Rhizobium inoculant Nitragina and the micronutrient fertilizer Photrel on root parameters depending on crop stands. Our findings revealed that Photrel and the combination of Nitragina and Photrel had an impact on the root system of pea. Klimek-Kopyra et al. (2015a) observed that, for pea grown in intercrops, there were as much as $70 \%$ of pea roots under drought conditions in the root fractions below $0.5 \mathrm{~mm}$. In this study, and also in general, RLD did not differ among years, whereas foliar fertilization with Photrel increased the RLD of pea in the root fractions of $0.1-0.5 \mathrm{~mm}$. In addition, we showed that the RLD differed between crop stands, with pea having a lower RLD in the root fractions of $0.1-1 \mathrm{~mm}$ when grown as pure crop stand compared to an intercrop with linseed.

The number of root nodules per plant differed among years but was not affected by crop stand and treatment. Farzaneh et al. (2009) also reported a year effect on root nodule number. The missing increase in root nodules per plant with Rhizobium inoculation indicated that rhizobia strains suitable for pea infection were present in the soil (cf. Farzaneh et al., 2009). Also the missing effect of the foliar fertilizer Photrel, which contains several micronutrients, might be explained by the high content of available nutrients in the experimental soil. Fertilization with sulfur can increase both the number and dry matter weight of root nodules of pea (Zhao et al., 1999; Scherer et al., 2006). Crop stand did not affect the number of root nodules per plant, whereas Zhao et al. (2020) reported that the number of root nodules per plant of pea increased with increasing density of intercropped maize.

\section{Conclusions}

The application of Rhizobium inoculation (Nitragina) or foliar fertilization (Photrel) and intercropping can affect root parameters of pea. Intercropping of pea with linseed resulted in a higher RDL of pea in the root fractions of 0.1-1 mm compared to pure pea and pea/wheat. Also, MRD was higher and RDM tended to be higher in pea/ linseed than in pea/wheat. Foliar fertilization with Photrel resulted in a higher RLD in the root fractions of $0.1-$ $0.5 \mathrm{~mm}$ than with Rhizobium inoculation using Nitragina. MRD was not affected by the treatments, but a combination of Nitragina + Photrel increased RDM in 1 year. The number of root nodules per plant was not affected by crop stands or treatments but varied among years. The same observation has been made for MRD and RDM but not for RLD. Intercropping of pea with linseed and the application of a foliar fertilizer might be a strategy to improve pea root characteristics.

\section{Acknowledgments}

The study was supported by the Ministry of Science and Higher Education in Poland (Project no. N N310 151837).

\section{References}

Annicchiarico, P. and E. Piano (2004): Indirect selection for root development of white clover and implications for drought tolerance. Journal of Agronomy and Crop Science 190, 28-34.

Benjamin J.G. and D.C. Nielsen (2006): Water deficit effects on root distribution of soybean, field pea and chickpea. Field Crops Research 97, 248-253.

Bodner G., Leitner, D., Nakhforoosh, A., Sobotik, M., Moder, K. and H.-P. Kaul (2013): A statistical approach to root system classification. Frontiers in Plant Science 4, 292.

Craine, J. and R. Dybzinski (2013): Mechanisms of plant competition for nutrients, water and light. Functional Ecology 27, 833-840.

Ebrahimi, E., Kaul, H.-P., Neugschwandtner, R.W. and A. Dabbagh Mohammadi Nassab (2017): Productivity of wheat (Triticum aestivum L.) intercropped with rapeseed (Brassica napus L.). Canadian Journal of Plant Science 97, 557-568. 
Eissenstat, D.M. and R.D. Yanai (1997): The ecology of root lifespan. Advances in Ecological Research 27, 1-60.

Farzaneh M., Wichmann S., Vierheilig H. and H.-P. Kaul (2009): The effects of arbuscular mycorrhiza and nitrogen nutrition on growth of chickpea and barley. Pflanzenbauwissenschaften 13, 15-22.

Fernández V. and T. Eichert (2009): Uptake of hydrophilic solutes through plant leaves: current state of knowledge and perspectives of foliar fertilization. Critical Reviews in Plant Sciences 28, 36-68.

Ho, M., Rosas, J., Brown, K. and J.P. Lynch (2005): Root architectural tradeoffs for water and phosphorus acquisition. Functional Plant Biology 32, 737-748.

Ingram, K.T., Bueno, F.O., Namuco, O.S., Yambao, E.B. and C.A. Beyrouty (1994): Rice root traits for drought resistance and their genetic variation. In: Kirk, G.J.O. (Ed.): Rice Roots: Nutrient and Water use. International Rice Research Institute, Los Banos, Manila, Philippines, pp. 67-77.

Jensen, E.S., Ambus, P., Bellostas, N., Boisen, S., Brisson, N. and G. Corre-Hellou (2007): Intercropping of cereals and grain legumes for increased production, weed control, improved product quality and prevention of N-losses in European organic farming systems. In: Andreasen, C.B., Elsgaard, L., Sørensen, L.S. and G. Hansen (Eds.): Proceedings, Danish Research Centre for Organic Food and Farming (DARCOF), Tjele, pp. 180-181.

Klimek-Kopyra, A., Kulig, B., Głąb, T., Stokłosa, A. and T. Zając (2015a): Vertical distribution of linseed and legumes roots system in pure sowing or mixture. Acta Agrobotanica 68, 43-52.

Klimek-Kopyra, A., Kulig, B., Oleksy, A. and T. Zając (2015b): Agronomic performance of naked oat (Avena nuda L.) and faba bean intercropping. Chilean Journal of Agricultural Research 75, 168-173.

Klimek-Kopyra, A., Strojny, J., Zając, T., Ślizowska, A., Klimesova, J. and R.W. Neugschwandtner (2017): Ordinal regression model for pea seed mass. Die Bodenkultur: Journal of Land Management, Food and Environment 68, 81-87.

Klimek-Kopyra, A., Oleksy, A., Zając, T., Głąb, T. and R. Mazurek (2018a): Impact of inoculant and foliar fertilization on root system parameters of pea (Pisum sativum L.). Polish Journal of Soil Science 51, 23-39.

Klimek-Kopyra, A., Oleksy, A., Zając, T. and B. Kulig (2018b): Value of different vegetative indices (NDVI, GAI) usage in assessment of productive potential of pea (Pisum sativum L.) at different growth stages under varying management practices. Acta Agrobotanica 71, $1-13$.

Klimek-Kopyra, A. and K. Rębilas (2019): Dependence of pea root mass distribution on weather conditions under varying levels of phosphorus application. International Agrophysics 32, 365-372.

Klimek-Kopyra, A., Zając, T., Mańkowski, J. and A. Oleksy (2020): Comparison of intercropping and pure cropping as determinants of the stem and canopy foliage of linseed (Linum usitatissimum L.) and pea (Pisum sativum L.) cultivars and their productivity. Journal of Natural Fibers, DOI: 10.1080/15440478.2020.1726246.

Lynch, J.P. (2013): Steep, cheap and deep: An ideotype to optimize water and $\mathrm{N}$ acquisition by maize root systems. Annals of Botany 112, 347-357.

Lynch, J.P. (2018): Rightsizing root phenotypes for drought resistance. Journal of Experimental Botany 69, 3279-329.

Laio, F., D'Odorico, P. and L. Ridolfi (2006): An analytical model to relate the vertical root distribution to climate and soil properties. Geophysical Research Letters 33, L18401.

Matsui, T. and B.B. Singh (2003): Root characteristics in cowpea related to drought tolerance at the seedling stage. Experimental Agriculture 39, 29-38.

Neugschwandtner, R.W. and H.-P. Kaul (2016a): Concentrations and uptake of macronutrients by oat and pea in intercrops in response to $\mathrm{N}$ fertilization and sowing ratio. Archives of Agronomy and Soil Science 67, 1-15.

Neugschwandtner, R.W. and H.-P. Kaul (2016b): Concentrations and uptake of micronutrients by oat and pea in intercrops in response to $\mathrm{N}$ fertilization and sowing ratio. Die Bodenkultur: Journal of Land Management, Food and Environment 67, 1-15.

Neugschwandtner, R.W. and H.-P. Kaul (2015): Nitrogen uptake, use and utilization efficiency by oat-pea intercrops. Field Crops Research 179, 113-119.

Neugschwandtner, R.W. and H.-P. Kaul (2014): Sowing ratio and $\mathrm{N}$ fertilization affect yield and yield components of oat and pea in intercrops. Field Crops Research 155, 159-163.

Qin, R.J., Stamp, P. and W. Richner (2004): Impact of tillage on root systems of winter wheat. Agronomy Journal 96, 1523-1530.

Qaderii, M., Martel, A. and S. Dixon (2019): Environmental factors influence plant vascular system and water regulation. Plants 65, 1-23. 
Rudnicki, F. and D. Jaskulski (2006): Evaluation of the competitive effect between crops and weeds in field. Acta Scientarum Polonaru, Agricultura 5, 45-52.

Scherer, H.W., Pacyna, S., Manthey, N. and M. Schulz (2006): Sulphur supply to peas (Pisum sativum L.) influences symbiotic $\mathrm{N}_{2}$ fixation. Plant Soil Environment 52, 72-77.

Smucker, A.J.M. (1993): Soil environmental modifications of root dynamics and measurement. Annual Review of Phytopathology 31, 191-216.

Songsri, P., Vorasoot, N., Jogloy, S., Kesmala, T., Akkasaeng, C., Patanothai, A. and C.C. Holbrook (2009): Evaluation of yield and reproductive efficiency in peanut (Arachis hypogaea L.) under different available soil water. Asian Journal of Plant Sciences 8, 465-473.

Tron, S. Bodner, G., Laio, F., Ridolfi, L. and D. Leitner (2013): Can diversity in root architecture explain plant water use efficiency? A modeling study. Ecological Modelling 312, 200-210.

Weinbaum, S. (1988): Foliar nutrition of fruit trees. In: Neumann, P.M. (Ed.): Plant growth and leaf-applied chemicals. CRC Press, Boca Raton, Florida, pp. 81-100.

Wójcik P. (2004): Uptake of mineral nutrients from foliar fertilization. Journal of Fruit and Ornamental Plant Research 12, 201-218.
Zając, T., Klimek-Kopyra, A., Mańkowski, J., Oleksy, A. and P. Micek (2018): A comparison of the chemical composition of the seeds of linseed and pea cultivars grown in pure stand or mixture. Journal of Natural Fibers 18, 1-9.

Zając, T., Klimek-Kopyra, A., Oleksy, A., Stokłosa, A., Kulig, B. (2012): Morphological-developmental reaction and productivity of plants and canopy of semileafless pea (Pisum sativum L.) after seed vaccination with Rhizobium and foliar micronutrient fertilization. Journal of Applied Botany and Food Quality 85, 188-197.

Zając c, T., Oleksy, A., Stokłosa, A., Klimek-Kopyra, A. and B. Kulig (2013): The development competition and productivity of linseed and pea-cultivars grown in a pure sowing or in a mixture. European Journal of Agronomy 44, 22-31.

Zhao, C., Fan, F., Coulter, J.E., Yin, W., Hu, F., Yu, A., Fan, H. and Q. Chai (2020): High maize density alleviates the inhibitory effect of soil nitrogen on intercropped pea. Agronomy, 10, 248.

Zhao, F.J., Wood, A.P. and S.P. McGrath (1999): Effects of sulphur nutrition on growth and nitrogen fixation of pea (Pisum sativum L.). Plant and Soil 212, 209-219. 